Article

\title{
A Population-Based Study on the Association between Periodontal Disease and Major Lifestyle-Related Comorbidities in South Korea: An Elderly Cohort Study from 2002-2015
}

\author{
Jae-Hong Lee * (D) and Seong-Nyum Jeong \\ Department of Periodontology, Daejeon Dental Hospital, Institute of Wonkwang Dental Research, \\ College of Dentistry, Wonkwang University, Daejeon 35233, Korea; seongnyum@wku.ac.kr \\ * Correspondence: ljaehong@gmail.com; Tel.: +82-42-366-1114; Fax: +82-42-366-1115
}

Received: 6 October 2020; Accepted: 28 October 2020; Published: 29 October 2020

\begin{abstract}
This study determined the association between periodontal disease (PD) and major lifestyle-related comorbidities (LCs) using the database of the nationwide population-based National Health Insurance Service-Elderly Cohort 2002-2015. A nationwide representative sample comprising 558,147 participants, aged 60 years, was analyzed. Univariate and multivariate logistic regression analyses adjusted for sociodemographic and economic factors (sex, age, household income, insurance status, health status, and living area) and major LCs (hypertension, diabetes mellitus, rheumatoid arthritis, osteoporosis, cerebral infarction, angina pectoris, myocardial infarction, erectile dysfunction, lipoprotein disorder, and obesity) were used to determine the association between PD and major LCs. Elderly participants with PD had a higher risk of major LCs (hypertension: odds ratio $(\mathrm{OR})=1.40$, diabetes mellitus: $\mathrm{OR}=1.22$, rheumatoid arthritis: $\mathrm{OR}=1.16$, osteoporosis: $\mathrm{OR}=1.37$, erectile dysfunction: $\mathrm{OR}=1.73$, lipoprotein disorder: $\mathrm{OR}=1.50$, and obesity: $\mathrm{OR}=1.59$ ). Our longitudinal cohort study provided evidence that PD was significantly associated with major LCs in elderly participants. In particular, the association between PD and erectile dysfunction had the highest OR in the multivariate analyses.
\end{abstract}

Keywords: aged; comorbidity; periodontal diseases; periodontitis; risk factors

\section{Introduction}

Periodontal disease (PD) is a highly prevalent and multifactorial chronic inflammatory oral disorder with a complex etiology involving both bacterial and environmental components [1,2]. PD causes destruction of tooth-supporting tissues, including the alveolar bone, cementum, and periodontal ligament, and finally leads to tooth loss, significantly reducing masticatory function and quality of life [3].

As a result of rapidly aging population, urbanization, and industrialization, many chronic inflammatory and infectious diseases have become more prevalent worldwide [4]. Lifestyle-related comorbidities (LCs) or diseases, such as cardiovascular disease, hypertension, obesity, and diabetes mellitus, significantly deteriorate the quality of life and are a major cause of morbidity and mortality in elderly individuals [5].

PD and LCs are among the most common non-communicable diseases and are closely related to factors such as poor dietary habits and smoking, and both diseases are regarded as risk factors or indicators that affect the outcome of one another [6,7]. In recent years, epidemiological and pathological studies have documented the bidirectional relationship between PD and LCs and have described several similar etiological and pathophysiological pathways between the conditions [6,7]. In particular, 
remarkable associations have been reported between LCs and gram-negative periodontal pathogens, including Aggregatibacter actinomycetemcomitans and Porphyromonas gingivalis [8,9].

Substantial evidence has shown that bacteria, endotoxins, and serum and salivary mediators associated with PD can directly or indirectly lead to bacteremia, systemic inflammation, and endothelial dysfunction [10-13]. In particular, chronic and severe PD has a significantly increased risk of developing LCs after adjusting for many of the confounding risk factors [14]. Nevertheless, the underlying plausible mechanisms linking PD with LCs are not fully understood, and there is limited evidence available from controlled trials. In the past decades, various cohort studies have confirmed the association between periodontal disease and LCs, but large cohort studies involving elderly people aged 65 years or older are still insufficient to clarify the causative relationship. Therefore, we designed a retrospective cohort study using the database of the nationwide population-based National Health Insurance Service-Elderly Cohort (NHIS-EC) to investigate the association between PD and major LCs among elderly participants in South Korea.

\section{Materials and Methods}

\subsection{Study Design and Data Collection}

This study conformed to the Strengthening the Reporting of Observational Studies in Epidemiology (STROBE) guidelines for reporting observational cohort studies (www.strobe-statement.org) and was approved by the Institutional Review Board of Daejeon Dental Hospital, Wonkwang University (approval no. W1908/003-001). This retrospective elderly cohort study used data collected over 14 years (2002-2015) from the National Health Insurance Service Sharing Service (NHISS, https://nhiss.nhis.or.kr). Four categories of data were extracted from the NHIS-EC database: sociodemographic and economic information, insurance status, health checkup examination, and medical and dental records. Details of the NHIS cohort profile have been described in a reference study [15].

\subsection{Study Participants}

The nationwide database from the South Korean mandatory National Health Insurance Program consists of a representative sample of 558,147 participants, with $10 \%$ of elderly people aged 60 years and above. We identified participants who had received a diagnosis of acute or chronic PD based on the following International Classification of Diseases, 11th Revision (ICD-11) diagnostic codes: acute periodontitis (DA0C.0), aggressive periodontitis (DA0C.1), periodontosis (DA0C.2), necrotizing PD (DA0C.3), abscess of the periodontium (DA0C.4), linear gingival erythema (DA0C.5), other specified PD (DA0C.Y), and unspecified PD (DA0C.Z). PD was diagnosed clinically and radiographically on the basis of probing depth, clinical attachment level, and bone loss in accordance with the guidelines of the American Academy of Periodontology [16]. In addition, only participants with these codes who were insured at least three times between 2002 and 2005 were included to increase diagnostic accuracy.

All participants were followed-up from the entry date of the cohort until the date of LC diagnosis (according to the following ICD-11 diagnostic codes: hypertension (BA00), diabetes mellitus (5A10-5A14), rheumatoid arthritis (FA20), osteoporosis (FB83.1), cerebral infarction (8B11), angina pectoris (BA40), acute and subsequent myocardial infarction (BA41-BA42), erectile dysfunction (ED) (HA01.1), lipoprotein disorder (OC80.00, 5C81Z, 5C8Y, and 5C8Z), and obesity (5B81)), migration, mortality, or the end of the study period.

\subsection{Covariates}

The covariates included in the analyses were sex (male and female), age (six groups: age 60-64, 65-69, 70-74, 75-79, 80-84, and $\geq 85$ years), household income (five groups: classified according to the insurance fee imposed on each household, with Medical Aid Program (MAP) beneficiaries in the first quintile), insurance status (three groups: those classified as MAP and NHIS (employees and self-employed)), health status (two groups: those classified as healthy and those with major and 
minor disabilities according to the Handicapped Welfare Law), and living area (three groups: those living in Seoul ( $\geq 10$ million residents), metropolitan areas ( $\geq 1$ million residents), and other areas $(<1$ million residents)).

\subsection{Statistical Analysis}

The chi-squared test was used to assess differences in categorical variables between the PD and periodontally healthy participants. Univariate and multivariate logistic regression analyses adjusted for sociodemographic and economic factors (sex, age, household income, insurance status, health status, and living area) and LCs (hypertension, diabetes mellitus, rheumatoid arthritis, osteoporosis, cerebral infarction, angina pectoris, myocardial infarction, erectile dysfunction, lipoprotein disorder, and obesity) were used to examine the risk factors for PD, and the results were presented as odds ratios (ORs) and 95\% confidence intervals (CIs). All statistical analyses were performed using SAS software (version 9.4, SAS Institute, Cary, NC, USA), and a $p$ value $<0.05$ was considered to be statistically significant.

\section{Results}

\subsection{Sociodemographic and Economic Factors Associated with Periodontal Disease}

The sociodemographic and economic factors of the PD and periodontally healthy participants are summarized in Table 1. Among the 558,147 South Korean participants originally included in 2002-2015, 149,785 participants were diagnosed with PD. Those aged 60-64 years $(n=75,716)$ accounted for $50.5 \%$ of the surveyed participants. Furthermore, 51,248 (34.2\%) of the participants were in the fifth quintile of household income, 83,003 (55.4\%) were employed, 149,302 (99.7\%) had a healthy health status, and $78,957(52.7 \%)$ lived in areas with $<1,000,000$ residents.

Table 1. Sociodemographic and economic factors associated with periodontal disease (PD).

\begin{tabular}{|c|c|c|c|c|c|}
\hline \multirow{2}{*}{ Variables } & \multicolumn{2}{|c|}{ PD Participants } & \multicolumn{2}{|c|}{ Periodontally Healthy Participants } & \multirow{2}{*}{$p$ Value } \\
\hline & $n$ & $\%$ & $n$ & $\%$ & \\
\hline Total & 149,785 & 100.0 & 408,362 & 100.0 & \\
\hline \multicolumn{6}{|l|}{ Sex } \\
\hline Male & 65,817 & 43.9 & 167,765 & 40.3 & \multirow{2}{*}{$<0.001$} \\
\hline Female & 83,968 & 56.1 & 243,597 & 59.7 & \\
\hline \multicolumn{6}{|l|}{ Age group (years) } \\
\hline 60-64 & 75,716 & 50.5 & 120,400 & 29.5 & \multirow{6}{*}{$<0.001$} \\
\hline $65-69$ & 44,322 & 29.6 & 103,039 & 25.2 & \\
\hline $70-74$ & 20,179 & 13.5 & 77,478 & 19.0 & \\
\hline $75-79$ & 7234 & 4.8 & 53,983 & 13.2 & \\
\hline $80-84$ & 1970 & 1.3 & 33,245 & 8.1 & \\
\hline$\geq 85$ & 364 & 0.2 & 20,217 & 5.0 & \\
\hline \multicolumn{6}{|l|}{ Household income $^{1}$} \\
\hline First quintile & 26,179 & 17.5 & 104,610 & 25.6 & \multirow{5}{*}{$<0.001$} \\
\hline Second quintile & 17,264 & 11.5 & 53,158 & 13.0 & \\
\hline Third quintile & 21,944 & 14.7 & 59,686 & 14.6 & \\
\hline Fourth quintile & 33,150 & 22.1 & 81,155 & 19.9 & \\
\hline Fifth quintile & 51,248 & 34.2 & 109,753 & 26.9 & \\
\hline \multicolumn{6}{|l|}{ Insurance status } \\
\hline MAP beneficiary & 6057 & 4.0 & 39,369 & 9.6 & \multirow{3}{*}{$<0.001$} \\
\hline NHIS, employed & 83,003 & 55.4 & 194,955 & 47.7 & \\
\hline $\begin{array}{l}\text { NHIS, } \\
\text { self-employed }\end{array}$ & 60,725 & 40.5 & 174,038 & 42.6 & \\
\hline
\end{tabular}


Table 1. Cont.

\begin{tabular}{lccccc}
\hline \multirow{2}{*}{ Variables } & \multicolumn{2}{c}{ PD Participants } & \multicolumn{2}{c}{ Periodontally Healthy Participants } & \multirow{2}{*}{$\boldsymbol{p}$ Value } \\
\cline { 2 - 5 } & $\boldsymbol{n}$ & $\boldsymbol{\%}$ & $\boldsymbol{n}$ & $\boldsymbol{\%}$ & \\
\hline Health status ${ }^{2}$ & & & & & $<0.001$ \\
$\quad$ Healthy & 149,302 & 99.7 & 405,175 & 99.2 & \\
$\quad$ Disabled & 483 & 0.3 & 3187 & 0.8 & $<0.001$ \\
\hline Living area & & & & & \\
$\quad$ Seoul & 33,714 & 22.5 & 65,878 & 21.0 & \\
$\quad$ Metropolitan area & 37,114 & 24.8 & 85,758 & 62.9 & \\
$\quad$ Other areas & 78,957 & 52.7 & 256,726 & & \\
\hline
\end{tabular}

PD, periodontal disease; MAP, Medical Aid Program; NHIS, National Health Insurance Service. ${ }^{1}$ Quintiles based on the insurance fee imposed on each household (with MAP beneficiaries in the first quintile). ${ }^{2}$ Classification'based on the Handicapped Welfare Law in South Korea. ${ }^{3}$ Classification based on residency in Seoul $(\geq 10,000,000$ residents), metropolitan areas $(\geq 1,000,000$ residents), or other areas $(<1,000,000$ residents).

\subsection{Lifestyle-Related Comorbidities Associated with Periodontal Disease}

A higher prevalence of all surveyed LCs was noted in the PD participants compared to the periodontally healthy participants $(p<0.001)$ (Table 2$)$. The most prevalent LC among participants was hypertension ( $n=293,246 ; 52.5 \%)$, followed by osteoporosis $(n=187,904 ; 33.7 \%)$, lipoprotein disorder $(n=186,083 ; 33.3 \%)$, diabetes mellitus $(n=176,914 ; 31.7 \%)$, angina pectoris $(n=99,747 ; 17.9 \%)$, cerebral infarction $(n=96,873 ; 17.4 \%)$, rheumatoid arthritis $(n=73,609 ; 13.2 \%)$, acute myocardial infarction $(n=15,378 ; 2.8 \%)$, erectile dysfunction $(n=2,557 ; 0.5 \%)$, subsequent myocardial infarction $(n=876 ; 0.2 \%)$, and obesity $(n=667 ; 0.1 \%)$.

Table 2. Sociodemographic and economic factors associated with PD.

\begin{tabular}{lccccc}
\hline \multirow{2}{*}{ Variables } & \multicolumn{2}{c}{ PD Participants } & \multicolumn{2}{c}{ Periodontally Healthy Participants } & \multirow{p}{*}{$\boldsymbol{p}$ Value } \\
\cline { 2 - 5 } & $\boldsymbol{n}$ & $\mathbf{\%}$ & $\boldsymbol{n}$ & $\mathbf{\%}$ & \\
\hline Total & 149,785 & 100.0 & 408,362 & 100.0 & $<0.001$ \\
\hline Hypertension & 104,257 & 69.6 & 188,989 & 46.3 & $<0.001$ \\
Diabetes mellitus & 67,946 & 45.4 & 108,968 & 26.7 & $<0.001$ \\
Rheumatoid arthritis & 27,971 & 18.7 & 45,638 & 11.2 & $<0.001$ \\
Osteoporosis & 67,623 & 45.1 & 120,281 & 29.5 & $<0.001$ \\
Cerebral infarction & 33,467 & 22.3 & 63,406 & 15.5 & $<0.001$ \\
Angina pectoris & 39,547 & 26.4 & 60,200 & 14.7 & $<0.001$ \\
Myocardial & & & & & $<0.001$ \\
infarction & & & & 2.4 & $<0.001$ \\
$\quad$ Acute & 5433 & 3.6 & 9945 & 0.1 & $<0.001$ \\
$\quad$ Subsequent & 300 & 0.2 & 576 & 0.3 & $<0.001$ \\
Erectile dysfunction & 1373 & 0.9 & 1184 & 26.8 & 0.1 \\
Lipoprotein disorder & 76,465 & 51.0 & 109,618 & & \\
Obesity & 362 & 0.2 & 305 & & \\
\hline
\end{tabular}

The univariate analysis demonstrated significant associations between all LCs and PD $(p<0.001)$ (Figure 1). The multivariate regression analysis adjusted for sociodemographic and economic factors and LCs showed that cerebral infarction ( $\mathrm{OR}=0.99,95 \% \mathrm{CI}=0.97-1.00, p=0.356)$, angina pectoris $(\mathrm{OR}=0.86,95 \% \mathrm{CI}=0.78-0.95, p=0.003)$, acute myocardial infarction $(\mathrm{OR}=0.85,95 \% \mathrm{CI}=0.82-0.88$, $p<0.001)$, and chronic myocardial infarction ( $\mathrm{OR}=0.87,95 \% \mathrm{CI}=0.75-1.01, p=0.079)$ were not positively associated with PD. In contrast, all other LCs were significantly and positively associated with PD (Figure 2). 


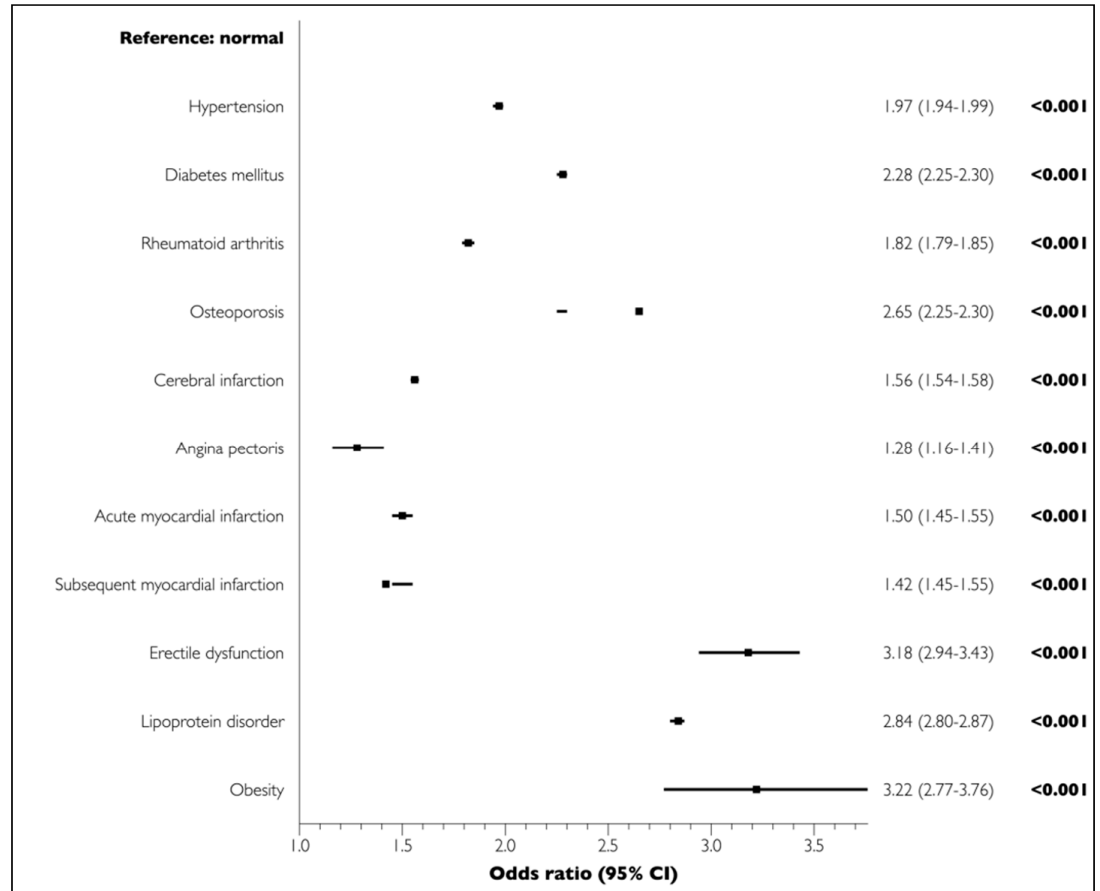

Figure 1. Associations of lifestyle-related comorbidities (LCs) with PD in elderly participants in the univariate analysis.

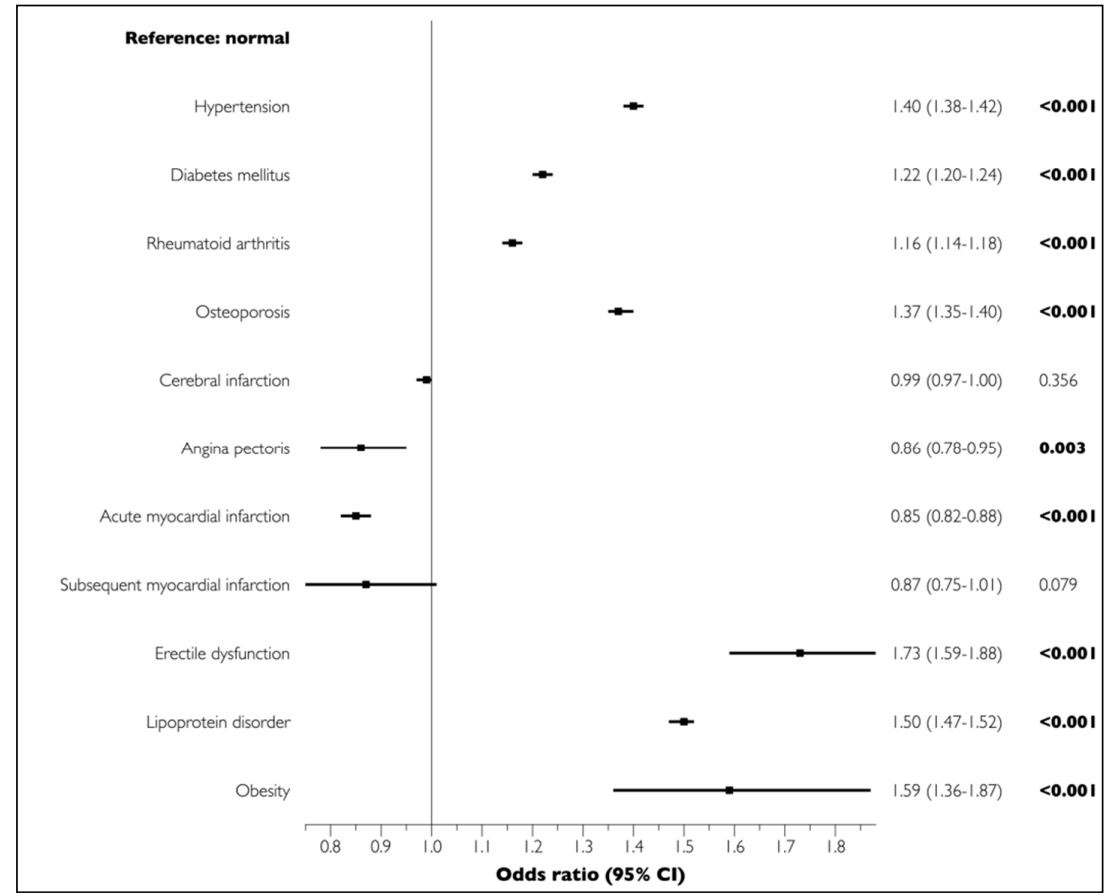

Figure 2. Associations of LCs with PD in elderly participants in the multivariate analysis. Boldface denotes statistical significance $(p<0.05)$. Multivariate logistic regression analyses adjusted for sociodemographic and economic factors (sex, age, household income, insurance status, health status, and living area) and LCs (hypertension, diabetes mellitus, rheumatoid arthritis, osteoporosis, cerebral infarction, angina pectoris, myocardial infarction, erectile dysfunction, lipoprotein disorder, and'obesity). 


\section{Discussion}

This long-term retrospective cohort study indicated that hypertension, diabetes mellitus, rheumatoid arthritis, osteoporosis, erectile dysfunction, lipoprotein disorder, and obesity were significantly and positively associated with PD when adjusted for sociodemographic and economic factors and major LCs. These findings are consistent with the results obtained in previous cohort studies involving young and middle-aged adults $[17,18]$.

Several possible mechanisms may be considered in establishing the relationship between PD and LCs [19-21]. First, inflammation plays an important role in the pathogenesis of local and systemic conditions. However, inflammatory mediators causing certain LCs are not well-defined. Systemic inflammation, as observed by an increase in the serum levels of C-reactive protein, and other biomarkers resulting from PD may be considered as one pathway by which this oral disease increases the risk of various LCs. Second, pathological oral bacteria may induce traumatic injury and cause irritation of the epithelium and mucosa, thereby playing a role in the subsequent progression of LCs. Other mechanisms, including a compromised immune system and inflammatory byproducts of periodontal pathogens, have also been proposed as possible associations.

Chronic and localized oral inflammation induces systemic inflammation and endothelial dysfunction, and is also intimately associated with ED. A number of potential risk factors, including ncreasing age, diabetes mellitus, hyperlipidemia, hypertension, and smoking, have been suggested to be important contributors to the development and progression of both PD and ED $[22,23]$. In the present study, the association between PD and ED showed the highest OR $(1.73,95 \% \mathrm{CI}=1.59-1.88, p<0.001)$ in the multivariate analysis. A systematic review, based on cross-sectional and randomized controlled trials, reported a positive association (OR $=1.53-3.35)$ between PD and ED, and a recent meta-analysis also confirmed that PD increased the risk of occurrence of $\mathrm{ED}(\mathrm{OR}=2.85,95 \% \mathrm{CI}=1.83-4.46, p<0.01)[24,25]$. Moreover, it was reported that the risk for $\mathrm{ED}$ prevalence was 3.07 times $(95 \% \mathrm{CI}=1.87-5.05, p<0.01)$ higher in Asian men [25].

In the present study, obesity, lipoprotein disorder, and hypertension had the second (OR $=1.59$, $95 \% \mathrm{CI}=1.36-1.87, p<0.001)$, third $(\mathrm{OR}=1.50,95 \% \mathrm{CI}=1.47-1.52, p<0.001)$, and fourth (OR $=1.40$, $95 \% \mathrm{CI}=1.38-1.42, p<0.001$ ) highest ORs of all surveyed LCs, respectively. Several epidemiological, experimental, and clinical studies have investigated and explored the potential role of obesity and hypertension in the development and progression of PD [26-28]. In one of the first animal experiments, obese rats showed the highest degree of alveolar bone loss, and obese hypertensive rats showed the most severe periodontal destruction [26]. A recent systematic review showed that hypertension was associated with $\mathrm{PD}(\mathrm{OR}=1.50,95 \% \mathrm{CI}=1.27-1.78, p<0.001)$, especially severe $\mathrm{PD}(\mathrm{OR}=1.64,95 \%$ $\mathrm{CI}=1.23-2.19, p<0.001)$ [29]. A systematic review and meta-analysis reported a positive association between PD and obesity ( $\mathrm{OR}=1.35,95 \% \mathrm{CI}=1.23-1.47, p<0.005)$, validating the role of obesity in the development of PD [27]. Another recent literature review suggested that obesity and metabolic diseases (such as dyslipidemia, hypertension, and dysglycemia) may be risk factors for the development and progression of PD [30-32].

The genetic basis of the association between PD and lipoprotein disorder is unclear and probably multifactorial; however, both diseases may be risk factors for obesity and poorly controlled diabetes mellitus [33]. Chronic PD produces endotoxins, which increases the serum levels of low-density lipoprotein cholesterol and has a negative effect on glycemic control [5,34]. Circulating serum levels of pro-inflammatory mediators, such as interleukin (IL)- $1 \beta$, IL-6, tumor necrosis factor- $\alpha$, C-reactive protein, and matrix metalloproteinases, are associated with both PD and lipoprotein disorders in elderly individuals [35,36].

In the present study, participants with PD exhibited an increased risk of osteoporosis ( $\mathrm{OR}=1.37$, $95 \% \mathrm{CI}=1.35-1.40, p<0.001)$. PD and osteoporosis have common lifestyle and biological risk factors, namely, old age, poor nutritional status, immunological diseases, and smoking [37]. Chronic and low-grade systemic inflammation may induce bone loss and reduce bone density, increasing the risk of osteoporotic fractures and promoting the progression of PD and tooth loss [38]. Recent systematic 
reviews have reported a probable association between PD and osteoporosis [39,40]. In particular, one systematic review found that chronic and severe PD was strongly associated with osteoporosis in postmenopausal women. However, further clinical studies are necessary to confirm this hypothesis [41].

Several studies have supported a biologically plausible association between PD and rheumatoid arthritis [42,43]. Both disorders are highly prevalent inflammatory and multifactorial diseases that share common risk factors and risk indicators. P. gingivalis lipopolysaccharide, which is involved in the development and progression of PD, was shown to induce the expression of pro-inflammatory cytokines and chemokines, thereby increasing the severity of rheumatoid arthritis [44]. This suggests that rheumatoid arthritis may be caused by dysbiosis of the periodontal microbiota $[44,45]$. In a recent study on the genetics of PD and rheumatoid arthritis, an allele of the interferon-gamma gene was identified as a significant disease-specific marker common to both diseases [43].

A recent umbrella review (review of systematic reviews or meta-analyses) reported that the most frequent correlation was found for PD with cardiovascular diseases [46]. As cardiovascular diseases, especially acute myocardial infarction, are associated with high mortality, morbidity, and serious sequelae in the elderly population, a significant number of elderly participants with these diseases would have been excluded from the NHIS-Elderly Cohort database. It was suspected that PD patients with severe and progressive cardiovascular disease were unlikely to visit dental clinics to be diagnosed and treated with PD, resulting in a low and insignificant negative correlation [47].

There are inherent limitations in conducting this retrospective observational cohort study based on the NHIS-EC database. First, many previous studies have clearly reported that smoking promotes the development and progression of PD and LCs [48-50]. Thus, a major limitation of the current study is that information on the smoking status of the participants was not included. Second, this retrospective cohort study did not assess dental records such as periodontal probing charts and radiographs, which limited the ability to diagnose the severity or extent of PD. In addition, the fact that the recently updated classification system for PD was not applied to the current cohort database can be considered as one of the limitations.

\section{Conclusions}

Our longitudinal cohort study suggests that PD is associated with a higher risk of most major LCs in elderly people. In particular, among the investigated LCs, erectile dysfunction seems to have a significant association with PD. However, no definitive conclusions could be drawn regarding the causative relationship between the underlying biological mechanisms of PD and LCs. Therefore, further large-scale and well-designed controlled clinical trials are needed to find conclusive evidence.

Author Contributions: Conceptualization, J.-H.L. and S.-N.J.; methodology, J.-H.L. and S.-N.J. software, J.-H.L. and S.-N.J.; validation, J.-H.L. and S.-N.J.; formal analysis, J.-H.L. and S.-N.J.; investigation, J.-H.L. and S.-N.J.; resources, J.-H.L. and S.-N.J.; data curation, J.-H.L. and S.-N.J.; writing-original draft preparation, J.-H.L. and S.-N.J.; writing-review and editing, J.-H.L. and S.-N.J.; visualization, J.-H.L. and S.-N.J.; supervision, J.-H.L. and S.-N.J.; project administration, J.-H.L.; funding acquisition, J.-H.L. All authors have read and agreed to the published version of the manuscript.

Funding: This work was supported by a National Research Foundation of Korea (NRF) grant funded by the Korean government (MSIT) (No. 2019R1A2C1083978).

Acknowledgments: This study used national sample cohort data of the National Health Insurance Service (NHIS-2019-2-268).

Conflicts of Interest: The authors declare no conflict of interest.

\section{References}

1. Khan, S.A.; Kong, E.F.; Meiller, T.F.; Jabra-Rizk, M.A. Periodontal diseases: Bug induced, host promoted. PLoS Pathog. 2015, 11, e1004952. [CrossRef] [PubMed] 
2. Kinane, D.F.; Stathopoulou, P.G.; Papapanou, P.N. Periodontal diseases. Nat. Rev. Dis. Primers 2017, 3, 17038. [CrossRef]

3. Kim, Y.T.; Choi, J.K.; Kim, D.H.; Jeong, S.N.; Lee, J.H. Association between health status and tooth loss in korean adults: Longitudinal results from the national health insurance service-health examinee cohort, 2002-2015. J. Periodontal Implant Sci. 2019, 49, 158-170. [CrossRef] [PubMed]

4. Kennedy, B.K.; Berger, S.L.; Brunet, A.; Campisi, J.; Cuervo, A.M.; Epel, E.S.; Franceschi, C.; Lithgow, G.J.; Morimoto, R.I.; Pessin, J.E.; et al. Geroscience: Linking aging to chronic disease. Cell 2014, 159, 709-713. [CrossRef] [PubMed]

5. Lee, J.H.; Jeong, S.N.; Choi, S.H. Predictive data mining for diagnosing periodontal disease: The korea national health and nutrition examination surveys (knhanes v and vi) from 2010 to 2015. J. Public Health Dent. 2019, 79, 44-52. [CrossRef]

6. Arigbede, A.O.; Babatope, B.O.; Bamidele, M.K. Periodontitis and systemic diseases: A literature review. J. Indian Soc. Periodontol. 2012, 16, 487-491. [CrossRef]

7. Sanz, M.; D'Aiuto, F.; Deanfield, J.; Fernandez-Aviles, F. European workshop in periodontal health and cardiovascular disease-scientific evidence on the association between periodontal and cardiovascular diseases: A review of the literature. Eur. Heart J. Suppl. 2010, 12, B3-CB12. [CrossRef]

8. Fiorillo, L.; Cervino, G.; Laino, L.; D’Amico, C.; Mauceri, R.; Tozum, T.F.; Gaeta, M.; Cicciu, M. Porphyromonas gingivalis, periodontal and systemic implications: A systematic review. Dent. J. 2019, 7, 114. [CrossRef]

9. Isola, G.; Polizzi, A.; Patini, R.; Ferlito, S.; Alibrandi, A.; Palazzo, G. Association among serum and salivary a. Actinomycetemcomitans specific immunoglobulin antibodies and periodontitis. BMC Oral Health 2020, 20, 283. [CrossRef]

10. Padilla, C.; Lobos, O.; Hubert, E.; Gonzalez, C.; Matus, S.; Pereira, M.; Hasbun, S.; Descouvieres, C. Periodontal pathogens in atheromatous plaques isolated from patients with chronic periodontitis. J. Periodontal Res. 2006, 41, 350-353. [CrossRef]

11. Zhang, B.; Khalaf, H.; Sirsjo, A.; Bengtsson, T. Gingipains from the periodontal pathogen porphyromonas gingivalis play a significant role in regulation of angiopoietin 1 and angiopoietin 2 in human aortic smooth muscle cells. Infect. Immun. 2015, 83, 4256-4265. [CrossRef]

12. Isola, G.; Alibrandi, A.; Curro, M.; Matarese, M.; Ricca, S.; Matarese, G.; Ientile, R.; Kocher, T. Evaluation of salivary and serum adma levels in patients with periodontal and cardiovascular disease as subclinical marker of cardiovascular risk. J. Periodontol. 2020. [CrossRef] [PubMed]

13. Isola, G.; Polizzi, A.; Iorio-Siciliano, V.; Alibrandi, A.; Ramaglia, L.; Leonardi, R. Effectiveness of a nutraceutical agent in the non-surgical periodontal therapy: A randomized, controlled clinical trial. Clin. Oral Investig. 2020. [CrossRef] [PubMed]

14. Huang, Y.; Cai, X.; Mai, W.; Li, M.; Hu, Y. Association between prediabetes and risk of cardiovascular disease and all cause mortality: Systematic review and meta-analysis. BMJ 2016, 355, i5953. [CrossRef]

15. Seong, S.C.; Kim, Y.Y.; Park, S.K.; Khang, Y.H.; Kim, H.C.; Park, J.H.; Kang, H.J.; Do, C.H.; Song, J.S.; Lee, E.J.; et al. Cohort profile: The national health insurance service-national health screening cohort (nhis-heals) in korea. BMJ Open 2017, 7, e016640. [CrossRef]

16. Krebs, K.A.; Clem, D.S., 3rd; American Academy of Periodontology. Guidelines for the management of patients with periodontal diseases. J. Periodontol. 2006, 77, 1607-1611. [CrossRef] [PubMed]

17. Lee, J.H.; Lee, J.S.; Park, J.Y.; Choi, J.K.; Kim, D.W.; Kim, Y.T.; Choi, S.H. Association of lifestyle-related comorbidities with periodontitis: A nationwide cohort study in korea. Medicine (Baltimore) 2015, 94, e1567. [CrossRef]

18. Lee, J.H.; Oh, J.Y.; Youk, T.M.; Jeong, S.N.; Kim, Y.T.; Choi, S.H. Association between periodontal disease and non-communicable diseases: A 12-year longitudinal health-examinee cohort study in south korea. Medicine (Baltimore) 2017, 96, e7398. [CrossRef]

19. Iacopino, A.M.; Cutler, C.W. Pathophysiological relationships between periodontitis and systemic disease: Recent concepts involving serum lipids. J. Periodontol. 2000, 71, 1375-1384. [CrossRef]

20. Seymour, G.J.; Ford, P.J.; Cullinan, M.P.; Leishman, S.; Yamazaki, K. Relationship between periodontal infections and systemic disease. Clin. Microbiol. Infect. 2007, 13 (Suppl. 4), 3-10. [CrossRef]

21. Hajishengallis, G. Periodontitis: From microbial immune subversion to systemic inflammation. Nat. Rev. Immunol. 2015, 15, 30-44. [CrossRef] 
22. Albandar, J.M. Global risk factors and risk indicators for periodontal diseases. Periodontol. 2000 2002, 29, 177-206. [CrossRef]

23. Selvin, E.; Burnett, A.L.; Platz, E.A. Prevalence and risk factors for erectile dysfunction in the us. Am. J. Med. 2007, 120, 151-157. [CrossRef] [PubMed]

24. Kellesarian, S.V.; Kellesarian, T.V.; Ros Malignaggi, V.; Al-Askar, M.; Ghanem, A.; Malmstrom, H.; Javed, F. Association between periodontal disease and erectile dysfunction: A systematic review. Am. J. Mens Health 2018, 12, 338-346. [CrossRef] [PubMed]

25. Zhou, X.; Cao, F.; Lin, Z.; Wu, D. Updated evidence of association between periodontal disease and incident erectile dysfunction. J. Sex Med. 2019, 16, 61-69. [CrossRef] [PubMed]

26. Perlstein, M.I.; Bissada, N.F. Influence of obesity and hypertension on the severity of periodontitis in rats. Oral Surg. Oral Med. Oral Pathol. 1977, 43, 707-719. [CrossRef]

27. Chaffee, B.W.; Weston, S.J. Association between chronic periodontal disease and obesity: A systematic review and meta-analysis. J. Periodontol. 2010, 81, 1708-1724. [CrossRef] [PubMed]

28. Keller, A.; Rohde, J.F.; Raymond, K.; Heitmann, B.L. Association between periodontal disease and overweight and obesity: A systematic review. J. Periodontol. 2015, 86, 766-776. [CrossRef]

29. Martin-Cabezas, R.; Seelam, N.; Petit, C.; Agossa, K.; Gaertner, S.; Tenenbaum, H.; Davideau, J.L.; Huck, O. Association between periodontitis and arterial hypertension: A systematic review and meta-analysis. Am. Heart J. 2016, 180, 98-112. [CrossRef]

30. Lamster, I.B.; Pagan, M. Periodontal disease and the metabolic syndrome. Int. Dent. J. 2017, 67, 67-77. [CrossRef]

31. Srivastava, M.C.; Srivastava, R.; Verma, P.K.; Gautam, A. Metabolic syndrome and periodontal disease: An overview for physicians. J. Family Med. Prim. Care 2019, 8, 3492-3495. [CrossRef]

32. Jepsen, S.; Suvan, J.; Deschner, J. The association of periodontal diseases with metabolic syndrome and obesity. Periodontol. 2000 2020, 83, 125-153. [CrossRef] [PubMed]

33. Genest, J. Lipoprotein disorders and cardiovascular risk. J. Inherit. Metab. Dis. 2003, 26, 267-287. [CrossRef] [PubMed]

34. Zhou, X.; Zhang, W.; Liu, X.; Zhang, W.; Li, Y. Interrelationship between diabetes and periodontitis: Role of hyperlipidemia. Arch. Oral Biol. 2015, 60, 667-674. [CrossRef] [PubMed]

35. Preshaw, P.M.; Alba, A.L.; Herrera, D.; Jepsen, S.; Konstantinidis, A.; Makrilakis, K.; Taylor, R. Periodontitis and diabetes: A two-way relationship. Diabetologia 2012, 55, 21-31. [CrossRef]

36. Chee, B.; Park, B.; Bartold, P.M. Periodontitis and type ii diabetes: A two-way relationship. Int. J. Evid. Based Healthc. 2013, 11, 317-329. [CrossRef]

37. Choi, J.K.; Kim, Y.T.; Kweon, H.I.; Park, E.C.; Choi, S.H.; Lee, J.H. Effect of periodontitis on the development of osteoporosis: Results from a nationwide population-based cohort study (2003-2013). BMC Womens Health 2017, 17, 77. [CrossRef]

38. Wactawski-Wende, J. Periodontal diseases and osteoporosis: Association and mechanisms. Ann. Periodontol. 2001, 6, 197-208. [CrossRef]

39. Martinez-Maestre, M.A.; Gonzalez-Cejudo, C.; Machuca, G.; Torrejon, R.; Castelo-Branco, C. Periodontitis and osteoporosis: A systematic review. Climacteric 2010, 13, 523-529. [CrossRef]

40. Esfahanian, V.; Shamami, M.S.; Shamami, M.S. Relationship between osteoporosis and periodontal disease: Review of the literature. J. Dent. (Tehran) 2012, 9, 256-264.

41. Goyal, L.; Goyal, T.; Gupta, N.D. Osteoporosis and periodontitis in postmenopausal women: A systematic review. J. Midlife Health 2017, 8, 151-158. [CrossRef]

42. de Oliveira Ferreira, R.; de Brito Silva, R.; Magno, M.B.; Carvalho Almeida, A.; Fagundes, N.C.F.; Maia, L.C.; Lima, R.R. Does periodontitis represent a risk factor for rheumatoid arthritis? A systematic review and meta-analysis. Ther. Adv. Musculoskelet. Dis. 2019, 11, 1759720X19858514. [CrossRef] [PubMed]

43. Schulz, S.; Putz, N.; Jurianz, E.; Schaller, H.G.; Reichert, S. Are there any common genetic risk markers for rheumatoid arthritis and periodontal diseases? A case-control study. Mediators Inflamm. 2019, 2019, 2907062. [CrossRef]

44. Correa, J.D.; Fernandes, G.R.; Calderaro, D.C.; Mendonca, S.M.S.; Silva, J.M.; Albiero, M.L.; Cunha, F.Q.; Xiao, E.; Ferreira, G.A.; Teixeira, A.L.; et al. Oral microbial dysbiosis linked to worsened periodontal condition in rheumatoid arthritis patients. Sci. Rep. 2019, 9, 8379. [CrossRef] [PubMed] 
45. Hajishengallis, G.; Lambris, J.D. Complement and dysbiosis in periodontal disease. Immunobiology 2012, 217, 1111-1116. [CrossRef] [PubMed]

46. Seitz, M.W.; Listl, S.; Bartols, A.; Schubert, I.; Blaschke, K.; Haux, C.; Van Der Zande, M.M. Current knowledge on correlations between highly prevalent dental conditions and chronic diseases: An umbrella review. Prev. Chronic Dis. 2019, 16, E132. [CrossRef]

47. Freisinger, E.; Malyar, N.M.; Reinecke, H. Peripheral artery disease is associated with high in-hospital mortality particularly in males with acute myocardial infarction in a nationwide real-world setting. VASA 2016, 45, 169-174. [CrossRef]

48. Martinez-Canut, P.; Lorca, A.; Magan, R. Smoking and periodontal disease severity. J. Clin. Periodontol. 1995, 22, 743-749. [CrossRef]

49. Tanur, E. Effects of smoking on the prevalence and severity of periodontal disease. Tex. Dent. J. 2001, 118, 922-929.

50. Ambrose, J.A.; Barua, R.S. The pathophysiology of cigarette smoking and cardiovascular disease: An update. J. Am. Coll. Cardiol. 2004, 43, 1731-1737. [CrossRef]

Publisher's Note: MDPI stays neutral with regard to jurisdictional claims in published maps and institutional affiliations.

(C) 2020 by the authors. Licensee MDPI, Basel, Switzerland. This article is an open access article distributed under the terms and conditions of the Creative Commons Attribution (CC BY) license (http://creativecommons.org/licenses/by/4.0/). 